\title{
JOURNAL OF PHILOSOPHICAL STUDIES
}

Vol. I, No. I.

JANUARY 1926.

\section{EDITORIAL}

IN launching a new Journal upon the public, an explanation in justification of its appearance should be given. This happens to be a very simple one. Some few months ago the British Institute of Philosophical Studies was formed with the object of promoting the advancement of philosophical studies by teaching, discussion, and research. It was believed that there was an increasing number of thoughtful people in every walk of life turning wistfully to Philosophy for light on some of the problems with which modern civilization is beset. During the past nine months this belief has received confirmation by the growth of a membership of the Institute which now numbers many hundreds. Men of affairs, members of the learned societies and of the professions, representatives of literature, art, and of the worlds of industry and commerce, have joined with a large proportion of the professed philosophers of the day and some of the more philosophically minded men of science to form an institution which recognizes the cultivation and advancement of philosophical studies to be a matter of importance to the nation. A large number of the members live in the provinces and abroad; and hence are unable to avail themselves of the various courses of lectures provided by the Institute. Nevertheless they naturally desire to be kept in touch with its activities. It is therefore necessary to provide a Journal, which we hope will also be appreciated by many who are not actually members of the Institute. 


\section{JOURNAL OF PHILOSOPHICAL STUDIES}

It will be obvious that, since only a small minority have submitted to long and arduous training in metaphysics, a Journal which is to prove of value to the many must avoid being too severely technical, and aim at making philosophy intelligible to the well-informed student. This will be a guiding principle in the general policy of the Journal, and in every number it is hoped to have articles which can be fully appreciated by every educated person. No philosophical periodical, however, would be fulfilling its complete function if it did not welcome original contributions to any of the great themes with which Philosophy deals. It is, therefore, proposed to include articles which may be of special interest to the expert, and at the same time stimulating to the learner.

Besides contributions dealing with specific subjects, it is proposed from time to time to give accounts of what is being done in different fields of Philosophy, and to provide surveys, as complete as can be made, of philosophical literature in various languages. New books demanding special attention will be reviewed at length, and attention will be drawn to important articles appearing in periodicals.

The value of the study of Philosophy is not to be measured in terms of actual knowledge. Comprehensive truth is indeed the inspiring ideal of Philosophy, but even though the ideal be unrealizable, its pursuit has effects upon the mind which generously repay the toil involved in the quest. The quest for the ultimately real and for an understanding of the Universe begets a certain spirit of impartiality in judging all things, and this spirit, refined and mellowed in the domain of theory, tends to invade other regions of life. In the world of practice it takes on the garb of justice; in the realm of emotion it reveals itself as a form of universal love.

Should the Journal of Philosophical Studies prove of service in fostering the growth of a more widely diffused philosophical temper, which to many of our best minds is regarded as the supreme desideratum of our age, it will have justified its appearance. Inspired by such a purpose and sustained by hope, we are content to bide the judgment of time. 